\title{
An Ergonomic Focus on Children, Youth, and Education
}

The general public thinks of ergonomics in terms of physical tasks and arrangements, such as correctly positioning their desks and working spaces, investigating work tasks to determine their impact on musculoskeletal work-related injuries, and perhaps in the design of motor vehicles. Television commercials and advertisements have much to do with the perceptions. Advertisements tend to depict ergonomics as primarily applying to the physical aspects of an adult worksite or a product used by an adult. However, ergonomics is an equal opportunity science.

Ergonomics is the scientific process of designing products, places, and procedures to align with the physical, cognitive, cultural, and emotional capabilities and limitations of the target audience who will use them. When viewed in this way, it is clear that ergonomics is equally important and applicable to designing for persons of all age categories, including children. Ergonomics is also important in the design of processes and places where perhaps it has not been considered previously, such as in the field of education.

Some professional groups have long considered the specific needs of children. For example, school teachers and pediatric health care professionals design their class and exam rooms, curricula and teaching methods, and their interaction techniques to best connect with the children who come to them. However, it is only more recently that ergonomics professionals have identified designing for children to be an area of specialty practice [1]. Other design-oriented professionals, such as architects, city planners, manufacturers, and transportation specialists develop goods and services that are used by children. Yet, they may not have the breadth and depth of knowledge in child development to adequately design for them, or they may not choose to allocate their resources to conduct the usability trials that are necessary to determine whether specifications regarding performance goals for the design have been met.

Designing for children can be complex because each design must meet the child where he or she is in their current development, and also 'pull' them into their next stage of personal growth. The designed product, place, or process must concurrently offer opportunities to succeed and occasions to be challenged [2]. In addition, children are 'moving targets' as they grow and change rapidly, creating a necessity for the designer to understand and accommodate their developmental stages and growth patterns. Remaining aware of children's musculoskeletal, visual, auditory, perceptual, cognitive, and emotional development is a challenge for anyone, and the implications for design are not always immediately evident. Designing for children can move from a micro approach of designing a singular product to a macro approach of designing community safety, educational, or prevention programs. For example, the goal might be bicycle safety for children and the approach might include designing 1) safer bicycles and helmets, 2) community-based safety and exercise programs, and 3) bicycle paths. The need for ergonomics research and design for children is great; the span of information is daunting; the process is timeconsuming; and the results are priceless - for they apply to our greatest joy and the caretakers of the futureour children.

A second area of potential growth for the application of ergonomics is in education. The history of applying ergonomics to specific military training is extensive, with attention given to selection processes, augmented cognition, and smart systems, among others. Less attention has been given to ergonomic design applications in learning environments such as preschools, elementary schools, middle schools, high schools, and university level educational programs - even those of- 
fered within military environments. Yet, the area is rich for cooperative research and design between educators and ergonomics professionals [3-5].

Questions abound as to how learning occurs and what can be done to enhance learning and the transfer of learned information to other settings, and which classroom technologies boost learning and which simply cost more, but change nothing. In keeping with the basic ergonomic tenet 'know thy user', ergonomic design should focus on the individuals who will use the item, process, or space. In an educational program, this includes students, faculty, staff, and prospective employers of students, and may include usability testing with each group. In addition, new technologies introduce new questions on human/technology interactions, such as whether on-line learning environments are as effective as in-person environments, how to best present material (should the speaker been seen during a webinar or is hearing their voice and viewing their slides adequate), what 'blending' of learning best augments current student programs, and what the safety implications of technology use may be.

The articles in this special issue address ergonomics for children and for educational settings, moving between and among:

- design applications for low technology and high level technology,

- from singular products to school and community based interventions,

- from microergonomic applications to macroergonomic system design,

- for individuals and for families, and

- for young children, as well as for young adults.

A central processing theme threads through the articles, which defines the practice of ergonomics: gathering information (data), using the information to design for a target population, and testing the design [6]. Gathering information equates to analysis to discern whether there is a problem that requires a design solution. The design aspect refers to development of a practical solution to the problem, and may involve evaluating alternative solutions before selecting the "best" solution. Testing the design involves use of empirical processes and measures to ascertain whether the design solution, in fact, solves the problem. While not every article in this special issue moves through each of the three components, each article does touch upon at least one of the three components. Of course, the articles focus either on designing for children, for education, or for both.
In the articles for children, Mullick describes adroitly gathering information from US children and parents to design toys that are fun, and both meet and challenge a child's development, in his article on Inclusive Indoor Play. Awan and Nasrullah portray their creation of an intervention project that fostered communication between researchers and families, thus enriching iterative information used to improve working conditions for youth and adults using carpet looms in Pakistan. These two diverse articles use a similar data gathering approach (interviews and feedback) to approach and design for children's play and work, respectively.

Larger scale collective efforts are described in three articles. First, Sanders, Stolz, and Chacon-Baker describe their efforts to assist daycare center directors, parents and therapists to minimize children's exposure to lead. Second, Van Oss, Quinn, Viscosi, and Bretscher explore methods to involve children, families and communities in identifying pedestrian hazards and creating safer communities, through what could be described as 'participatory ergonomics'. Finally, Rice takes the research on what is known about children's behavior and biological characteristics, along with applied studies and explains the design, use, and testing of warnings for children and their caregivers.

In the four articles focusing on education and children or young adults, Smith hones in on improving performance of students from kindergarten through $12^{\text {th }}$ grade through educational design, using a systems approach. Feathers, Pavlovic-Veselinovic, and Hedge report on a unique study in which they explore the relationship of Serbian school children's reports of discomfort with their anthropometric, desk and chair measurements, and their grade levels. Moving from a macroergonomic perspective, to more microergonomic perspectives, Harris, Straker, and Pollock tackle the questions that surround computers use among youth - at school and home, identifying patterns of use and exposure, resulting in an article that is useful for both educational professionals and for parents and caregivers. Continuing the technology investigation, Feathers, Rollings, and Hedge investigate the postural variations and subjective evaluations of college-age and young adults' computer mouse use. Finally, Rice, Butler and Marra investigate the relationship between symptoms of attention deficit disorder and symptoms of oppositional defiant disorder with academic and physical performance of young military students, to determine whether this constitutes a problem in need of a design solution.

While ergonomics is a science, it is clear from these articles that it is also a problem solving, application- 
oriented process. Ergonomics emphasizes "the relationship(s) between physical and behavioral variables and the translation of behavioral principles into physical design principles" [6, p. 13]. The sine qua non is the practical use of scientific information, in this case applied to children and to education.

Guest Editor

Valerie Rice, PhD, CPE, OTR/L, FAOTA, FHFES,

$\mathrm{COL}(\mathrm{R})$

Chief, Army Research Laboratory HRED AMEDD

Field Element

2377 Greeley Rd, STE R

Ft. Sam Houston,

San Antonio, TX 78234-7731, USA

Tel.: +1 210-221-2635/2007

Fax: +1 210-295-0441

E-mail: valerie.rice1@us.army.mil

\section{References}

[1] Lueder R and Rice VJB. Ergonomics for children: Designing products and places for toddlers to teens. New York: Taylor \& Francis. 2008.

[2] Rice VJB and Lueder R. Designing products for children. In R. Lueder and VJB Rice (Eds). Ergonomics for children: Designing products and places for toddlers to teens. New York: Taylor \& Francis. 2008, 399-476.

[3] Smith TJ. The ergonomics of learning: educational design and learning performance, Ergonomics.2007; 50: 1530-1546.

[4] Watson J, Smith TJ, Kraemer, S, Halverson R, Woodcock A. Macroergonomics in education: On your mark, set, GO! Proceedings of the Human Factors and Ergonomics Society Annual Meeting. 2011; 55(1): 1042-1046.

[5] Rice VJB. Evaluating and designing education: A collaborative effort between educators and ergonomists. Proceedings of the Human Factors and Ergonomics Society Annual Meeting. 2009; 53(16): 1017-1021.

[6] Meister D. The practice of ergonomics: Reflections on a profession. 1997; Published by and available from the Board of Certification in Professional Ergonomics, P.O. Box 2811, Bellingham, WA 98227-2811. 